\title{
The Bleed ... Through the eyes of a child
}

Patricia Bell

Most health care professionals will regard treating a bleed with factor as a routine matter. But bleeds - and getting them treated - can still be a major stress for patients. Trish Bell takes a walk in Sam's shoes
Patricia Bell

Clinical Nurse Specialist

Southampton Haemophilia Centre

University Hospital Southampton NHS

Foundation Trust

Tremona Road

Southampton SO16 6YD

Email: Patricia.Bell@uhs.nhs.uk
I hope you're sitting comfortable,

I'll read my story out in full

Let me tell you who I am,

I'm 3 years old and I am Sam.

I like books and Lego and football,

I go two days to nursery school

I live at home with my sister and brother,

My gran, my gramps, my dad, my mother.

But this is what you need to know, My blood won't clot, it's far too slow Yesterday while in the park

(We came home late it was nearly dark)

I kicked the ball and scored a goal

And then I fell down in a hole

I jumped up quick and ran to dad

I really didn't feel too bad.

I went to bed soon after tea

And thought I had a funny knee

Today I woke early - that's the rule

To get all ready for nursery school

But oh dear something's happened to me

I've got an ouch in my knee

I try to put my foot on the floor

It's really hurting more and more.

My mum comes in when she hears me cry She sees my knee and she knows why It's OK Sam, I know what you need Some treatment, you have had a bleed So off to hospital, we go by car We don't have to go all that far But even though it is quite near I'd rather be any place but here.

We go to see Jo my special nurse But I can't think of anything worse, Be good says mum "my little treasure" While Jo uses a tape measure In order to try and discover If this knee is bigger than the other It is also feeling rather warm She says while writing on a form.

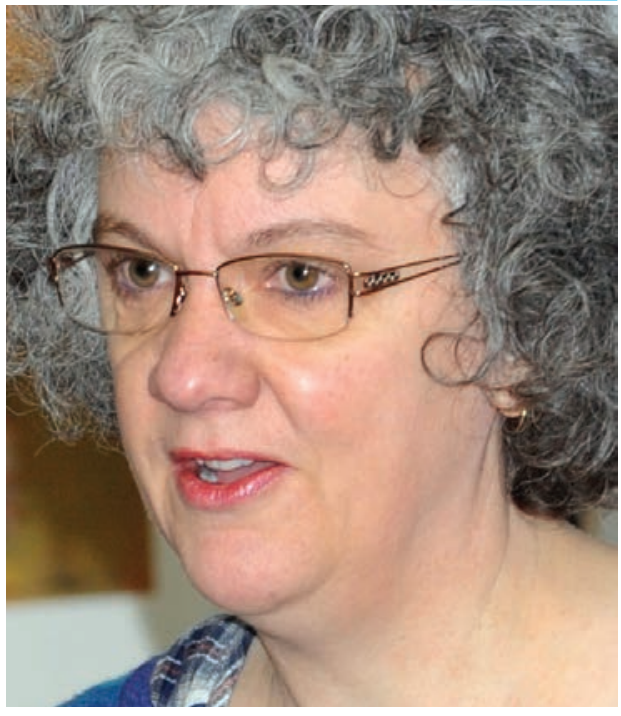

Another person enters - it's Lizzie 0 She's all right really, she's my physio Mum says "it's Sam's knee - he can't walk" I don't say a word I just can't talk We wait while Jo devises a plan Mum says she's proud of her little man Then I remember something - I mustn't forget

I ask to go to the toilet

Mum says that I will have to wait Until I've had my Factor eight So in my arm I have a shot Of medicine that makes my blood clot So then some news I like the best Upon our sofa I must rest

We begin to get ready now we can go We have to come back tomorrow.

So that is the story of my bleed And the treatment my leg did need At last, from hospital I am freed Oh dear, in my pants I have just wee'd!

\section{The Journal of Haemophilia Practice}

\author{
An open-access journal for sharing experience \\ in the care of people with bleeding disorders
}

www.haemjournal.com 